\title{
Accuracy of Different Metabolic Syndrome Definitions for Detecting Increased Carotid Intima- media Thickness in Peruvian Type 2 Diabetes Mellitus Subjects without Cardiovascular Disease.
}

\author{
Alberto Teruya-Gibu ( $\sim$ a.teruya.gibu@gmail.com ) \\ Hospital Nacional Edgardo Rebagliati Martins https://orcid.org/0000-0003-3816-4011 \\ Marlon Yovera-Aldana \\ Hospital Maria Auxiliadora \\ Diana Urquiza-Salvador \\ Hospital Nacional Edgardo Rebagliati Martins \\ Laurie Marcilla-Trullenque \\ Hospital Nacional Edgardo Rebagliati Martins
}

Original investigation

Keywords: diabetes, cardiovascular risk, carotid intima-media thickness, metabolic syndrome

Posted Date: November 5th, 2020

DOI: https://doi.org/10.21203/rs.3.rs-101451/v1

License: (c) (1) This work is licensed under a Creative Commons Attribution 4.0 International License.

Read Full License 


\section{Abstract}

Backrgound: To estimate the accuracy of metabolic syndrome definitions for detecting Carotid IntimaMedia thickness (CIMT) in Peruvian type 2 diabetes mellitus (T2DM) subjects without cardiovascular events.

Methods: We performed a cross-sectional evaluation of T2DM subjects from the endocrinology service of two reference health centers without stroke or coronary disease. . Bilateral carotid intima-media thickness was measure by B mode ultrasound one only operator. We performed four definitions of Metabolic Syndrome; 1. Cholesterol Education Program Adult Treatment Panel III (ATP III), 2. Harmonized criteria; 3. Gurka's Metabolic syndrome severity score (MSSS) formula. 4. Non-glucose modified MSSS. We calculated the area under the receiver operator curve (AUROC) for detecting increased CIMT ( $\geq 0.86 \mathrm{~mm}$ ) between metabolic syndrome definitions.

Results: We included 184 subjects with T2DM, 29\% were men with a mean age of $61.5 \pm 10.5$ years old. Median diabetes time was 10.8 years (IQR 4.8 to 19.4 ), and $26.8 \%$ achieved HbA1c goals. Non-glucose modified MSSS was the only definition significantly correlated with elevated CIMT $(r=0.19 ; p<0.01)$, and it showed the best accuracy for predicting elevated CIMT (AUC: 0.61, CI95\%: 0.52-0.70). Adjusting for age, sex, and $\mathrm{HbA1c}$, each point increase in the non-glucose MSSS Z score, the risk of altered CIMT increases by $59 \%$ RP 1.59 (Cl 95\% $1.09-2.35 ; p=0.017)$.

Conclusions: Non-glucose modified MSSS had a weak accuracy for elevated CIMT and was the best compared to ATP III, harmonized, and original MSSS. Further research on no MS-factors is required to predict better elevated CIMT.

\section{Background}

Cardiovascular disease (CVD) is the leading cause of mortality and morbidity in subjects with T2DM worldwide, and physicians call coronary equivalent to that subject with diabetes mellitus without coronary disease due to the high burden of disease. Subclinical cardiovascular disease (SCVD) determination, through Carotid intima-media (CIMT), coronary artery calcium (CAC), and presence of carotid plaque (CP), is associated with overt CVD, and this structural surrogate helps establish preventive strategies in primary care. Although CIMT has a lower predictive ability to detect overt CVD than CAC and $\mathrm{CP}(1)$, it might be considered the earliest structural change compared to the other subclinical parameters.

Metabolic syndrome (MS) is the aggregation of factors that include three of five components: waist circumference, glucose, HDL-cholesterol, triglycerides, and blood pressure (2). There are multiple definitions, varying by the cut-off points or one factor's predominance over another (2-4). Both T2DM and MS are associated with an increased prevalence of SCVD and overt CVD (5).

Furthermore, the reduction or aggregation of factors does not necessarily determine lower o higher cardiometabolic risk. Gurka et al.(7) designed a continuous score for the severity of metabolic syndrome 
specific to sex and ethnic group. According to factor analysis models, the metabolic syndrome severity score (MSSS) offers the advantage of converting those dichotomous variables (present or absent) into continuous numerical variables. This severity score has shown a good correlation with risk markers such

as insulin, adiponectin (8), and predictive value for cardiovascular risk in T2DM subjects (9), and chronic kidney disease (10).

For these reasons, it is critical to determine whether MSSS can predict the SCVD through the CIMT measurement and to clarify if this method could be used as an early tool for preclinical CVD. The absence of SCVD seems to attenuate the risk of overt CVD in subjects with T2DM and MS (6). Thus, we propose evaluating the accuracy of MSSS and other metabolic syndrome definitions to detect increased carotid intima-media thickness in Peruvian Type 2 diabetes mellitus subjects without CVD attending to a healthcare network social security system.

\section{Methods}

\subsection{Study design.}

The study was conducted as a cross-sectional design. All subjects gave written informed consent, and the study procedure followed the Helsinsky Declaration's agreements and was approved by the institutional ethics committee.

\subsection{Patient}

A total of 184 subjects with Diabetes mellitus were recruited from the outpatient clinic of the Edgardo Rebagliati Martins Hospital (HNERM) and the Diabetes and Hypertension Center (CEDHI) of the Social security Health System between January 2019 and January 2020. We included subjects older than 20 years and diagnosis of DM based on the ADA criteria. Those patients with a history of coronary artery disease, stroke, peripheral revascularization, or major amputation due to peripheral arterial disease were excluded. Likewise, those with DM1, LADA, NYHA III or IV heart failure, Child B or C liver disease, glomerular filtration rate $<60 \mathrm{ml} / \mathrm{min}$, acute or previous disease up to a range of 6 months, surgery \& radiotherapy at the cervical level and use of immunosuppressants or corticosteroids.

\subsection{Clinical and biochemical parameters}

Independent, trained medical personnel evaluated and collected data patients. Vital functions and anthropometric measurements were taken according to the established protocol. Waist circumference was measured with a tape scale according to the International Diabetes Federation (IDF) recommendations. A questionnaire was filled out directly from the patient regarding pathological history, lifestyle, comorbidities, and pharmacological treatment.

We obtained fasting blood samples for biochemical analyzes that included glucose, HbA1c, and lipid profile. The process was according to the central laboratory's routine method. 
We defined Metabolic syndrome according to ATP III and harmonized criteria and use the cut-of for abdominal perimeter obtained by Aschner in the harmonized MS criteria. We calculated MSSS (7) and non-glucose MSSS, according to Gurka et al (9), as Z-score through a spreadsheet.

\subsection{Measurement of MICT}

We measured CIMT by a single trained physician independent of data collection and processing using a Toshiba Nemio XG ultrasound scanner. We used a B-mode carotid ultrasound with a $7.5 \mathrm{MHz}$ linear transducer to assess the CIMT with standard insonation parameters. Patients were examined supine with the neck hyperextended and identified three segments in the anterior and posterior plane: $1 \mathrm{~cm}$ distal to the common carotid proximal to the carotid bifurcation, the bifurcation itself, $1 \mathrm{~cm}$ proximal to the internal carotid artery. We obtained the maximum average CIMT value from the far wall of both the right and left common carotid arteries and excluded CIMT $\geq 1.5 \mathrm{~mm}$

\subsection{Statistical analysis}

We presented categorical data as absolute and relative frequencies and consecutive data as mean and standard deviation or medians with interquartile range according to normal distribution. We described CIMT according to sex and age.

Also, we show the correlation between each SM definition with CIMT through Pearson's coefficient and its scatter charts. A value of $p<0.05$ was considered significant.

We performed area Under the Receiver Operator Curve (AUROC) of each MS definition to predict CIMT $\geq$ $0.86 \mathrm{~mm}$, and we calculated sensitivity and specificity according to the optimal cut-off value for each MS definitions.

We made a bivariate analysis for related and no related MS factors for CIMT and a regression model A adjusted to age and sex, and a regression model B adjusted to age, sex, and HbA1c.

\section{Results}

This study included 184 subjects with T2DM 29\% were men with a mean age of $61.5 \pm 10.5$ years old. Median diabetes time was 10.8 years (IQR 4.8 to 19.4) with a median HbA1c of 8.1\% (IQR 6.9 to 9.85), and only $26.8 \%$ achieved HbA1c goals. Smoker and sedentary lifestyle prevalences were $18.4 \%$ and $73.9 \%$, respectively. Antihypertensive drugs were used by $48.4 \%$ for used drugs, statins by $46.7 \%$, and acetylsalicylic acid by $27.7 \%$. Obesity prevalence was $42.3 \%$, with a median waist circumference of $98 \mathrm{~cm}$ (IQR 89.7-104). (Table 1) 
Tabla 1

Clinical-epidemiological characteristics in subjects with diabetes mellitus without cardiovascular disease at the Edgardo Rebagliati Hospital.

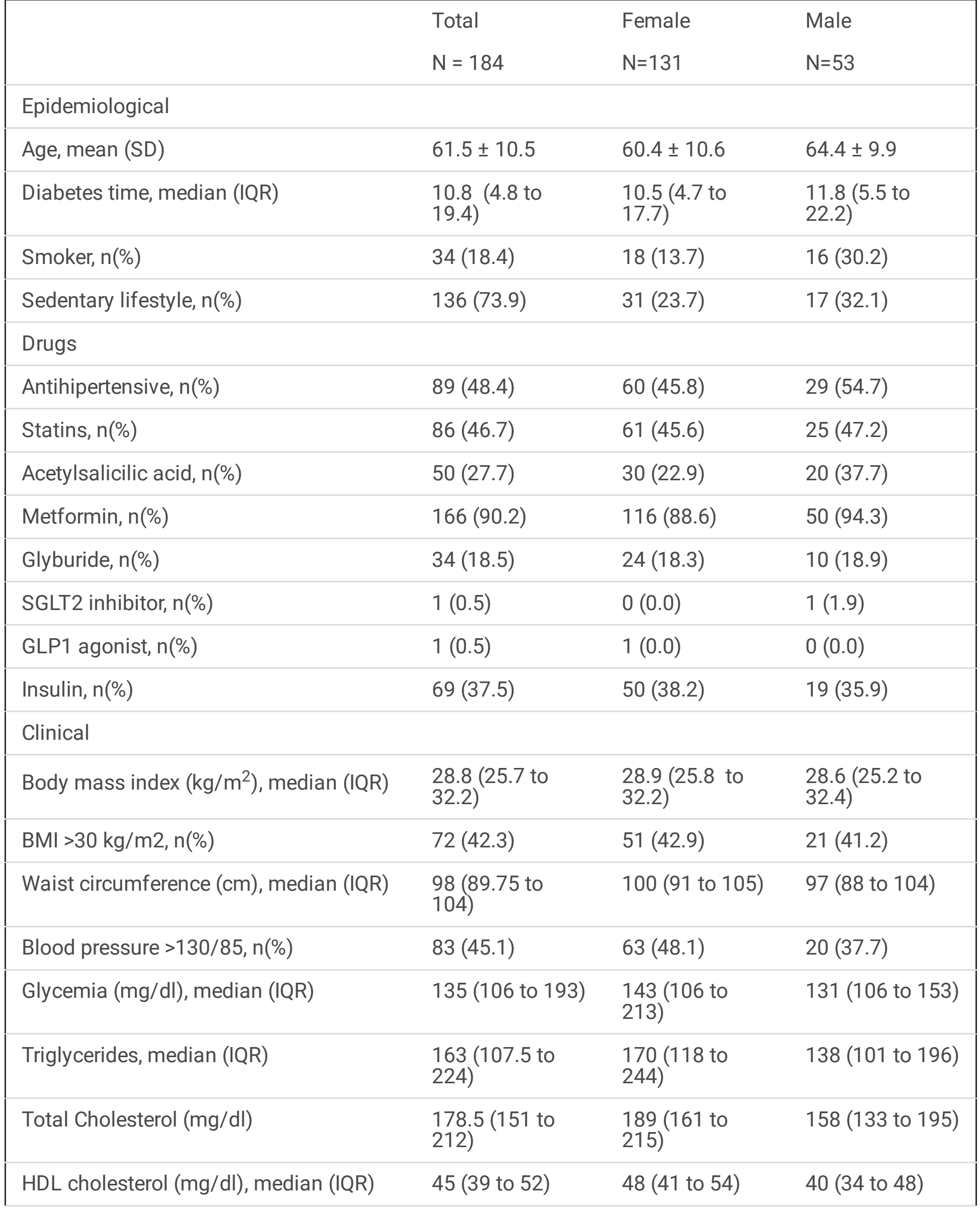




\begin{tabular}{|c|c|c|c|}
\hline LDL cholesterol (mg/dl), median (IQR) & 110 (89 to 139$)$ & $\begin{array}{l}116.5 \text { (94 to } \\
142)\end{array}$ & 101 (75 to 123$)$ \\
\hline $\begin{array}{l}\text { Glomerular filtration }(\mathrm{ml} / \mathrm{min} / 24 \mathrm{~h}) \text {, } \\
\text { median (IQR) }\end{array}$ & $\begin{array}{l}105.3(87.6 \text { to } \\
116.7)\end{array}$ & $\begin{array}{l}108.3 \text { (96 to } \\
\text { 117) }\end{array}$ & 94 (85 to 106$)$ \\
\hline A1C (\%), median (IQR) & 8.1 (6.9 to 9.85$)$ & $8.2(6.9$ to 10.1$)$ & 8 (6.85 to 9.4$)$ \\
\hline $\mathrm{A} 1 \mathrm{C}<7 \%$ & $48(26.7)$ & $34(26.6)$ & $14(26.9)$ \\
\hline \multicolumn{4}{|l|}{ Metabolic syndrome } \\
\hline ATP III criteria, n(\%) & $135(73.4)$ & $86(65.7)$ & $49(92.5)$ \\
\hline Harmonizing criteria, n(\%) & $145(78.8)$ & $96(73.3)$ & $49(92.5)$ \\
\hline \multicolumn{4}{|l|}{ MSSS } \\
\hline Z- score MSSS, median (IQR) & $\begin{array}{l}1.34(0.58 \text { to } \\
2.71)\end{array}$ & $\begin{array}{l}1.78(0.70 \text { to } \\
3.28)\end{array}$ & $\begin{array}{l}0.84(0.46 \text { to } \\
1.48)\end{array}$ \\
\hline Z-score MSSS $\geq 0, n(\%)$ & $110(59.8)$ & $119(90.8)$ & $47(88.7)$ \\
\hline $\begin{array}{l}\text { Z-score non-glucose MSSS, median } \\
\text { (IQR) }\end{array}$ & $\begin{array}{l}-1.08(-1.54 \text { to } \\
-0.54)\end{array}$ & $\begin{array}{l}-1.30(-1.66 \text { to } \\
-0.89)\end{array}$ & $\begin{array}{l}-0.43(-0.91 \text { to } \\
-0.19)\end{array}$ \\
\hline Z-score non-glucose MSSS $\geq 0, \mathrm{n}(\%)$ & $8(4.3)$ & $1(0.7)$ & $7(13.2)$ \\
\hline \multicolumn{4}{|l|}{ CIMT } \\
\hline (mm), Median (IQR) & $0.8(0.7$ to 0.9$)$ & $\begin{array}{l}0.75(0.7 \text { to } \\
0.85)\end{array}$ & $\begin{array}{l}0.85(0.7 \text { to } \\
0.95)\end{array}$ \\
\hline$\geq 0.86 \mathrm{~mm}, \mathrm{n}(\%)$ & $54(29.4)$ & $32(24.4)$ & $22(41.5)$ \\
\hline
\end{tabular}

Metabolic syndrome for ATP III criteria and Harmonized criteria were $73.4 \%$ and $78.8 \%$, respectively. The Median Z-score of the MSSS was 1.34 (IQR 0.58 to 2.71), and the median Z-score of the non-glucose MSSS was -1.08 (IQR - 1.54 to -0.54). The prevalence of MSSS and non-glucose MSSS above Z-score $\geq$ 0 were $59.8 \%$ and $4.3 \%$, respectively. (Table 1 )

Median CIMT was $0.8 \mathrm{~mm}$ (0.7-0.9), and the prevalence of elevated CIMT, defined by Rizzo ( $\geq 0.86 \mathrm{~mm})$, was $29.4 \%$. CIMT tends to increase according to age in both sexes (Fig. 1)

Only non-glucose MSSS showed a correlation with CIMT. $(r=0.19, p<0.01)$. (Fig. 2). Non-glucose MSSS obtained the best AUROC $0.61(0.52-0.70)$ compared with the other definitions. (Fig. 3). MSSS and Harmonized SM criteria included 0.5 in their confidence interval. A Z-score of -1.0 was the best cut-of 
point of non-glucose MSSS to predict elevated CIMT. This value had $57.4 \%$ and $60 \%$ of sensitivity and specificity, respectively. (Table 2)

Table 2

The area under the ROC of the Metabolic Syndrome Severity Score and Classic Definitions of Metabolic Syndrome for carotid medial intima thickness in Subjects with Diabetes Mellitus without Cardiovascular Disease at the Edgardo Rebagliati Martins Hospital.

\begin{tabular}{|llllc|}
\hline & AUC ROC & $\begin{array}{l}\text { Optimal cut- } \\
\text { off }\end{array}$ & Sensitivity & Specificity \\
\hline Metabolic síndrome & & & \\
\hline ATPIII MS criterio & $\begin{array}{l}0.59(0.51 \text { to } \\
0.68)\end{array}$ & 4 & $44.4 \%$ & $71.5 \%$ \\
\hline Harmonizing MS criteria & $0.56(0.47$ to & 4 & $53.7 \%$ & $59.2 \%$ \\
\hline $\begin{array}{l}\text { Metabolic Syndrome Severity } \\
\text { Score }\end{array}$ & & & & \\
\hline MSSS & $0.65)$ & & \\
\hline Non-glucose MSSS & $0.57)$ & & \\
\hline
\end{tabular}

Only systolic pressure was associated with CIMT (PR $1.01 \mathrm{CI} 95 \% 1.01$ to $1.03 ; p<0.000$ ) of the metabolic syndrome factors. Age, male sex, and the use of hypertensive drugs also showed association with CIMT (Table 3). 
Table 3

The prevalence rate of factors associated with elevated carotid medial intima thickness in subjects with diabetes mellitus without cardiovascular disease at the Edgardo Rebagliati Martins Hospital.

\begin{tabular}{|llll|}
\hline & PR & Cl 95\% & P \\
\hline Metabolic Syndrome factors & & & \\
\hline Glycemia $(\mathrm{mg} / \mathrm{dl})$ & 0.99 & $0.99-1.00$ & 0.52 \\
\hline Waist circunference (cm) & 1.00 & $0.98-1.02$ & 0.56 \\
\hline HDL colesterol (mg/dl) & 0.98 & $0.96-1.01$ & 0.12 \\
\hline Triglycerides (mg/dl) & 1.00 & $0.99-1.00$ & 0.33 \\
\hline Systolic blood pressure (mmHg) & 1.01 & $\mathbf{1 . 0 1 - 1 . 0 3}$ & $\mathbf{0 . 0 0 0}$ \\
\hline Other factors & & & \\
\hline Age (years old) & 1.06 & $\mathbf{1 . 0 3 - 1 . 0 9}$ & $\mathbf{0 . 0 0 0}$ \\
\hline Male sex & 1.69 & $\mathbf{1 . 0 9 - 2 . 6 3}$ & $\mathbf{0 . 0 1 8}$ \\
\hline Smoker & 1.12 & $0.65-1.95$ & 0.66 \\
\hline Diabetes time (years) & 1.01 & $0.99-1.03$ & 0.12 \\
\hline Body mass Index (kg/m2) & 0.99 & $0.95-1.05$ & 0.99 \\
\hline A1c (\%) & 0.95 & $0.86-1.06$ & 0.41 \\
\hline Total cholesterol (mg/dl) & 1.00 & $0.99-1.01$ & 0.95 \\
\hline LDL cholesterol & 0.99 & $0.99-1.00$ & 0.86 \\
\hline Hypertension drug & $\mathbf{2 . 1 3}$ & $\mathbf{1 . 3 1 - 3 . 4 7}$ & $\mathbf{0 . 0 0 2}$ \\
\hline Statins drug & 0.72 & $0.45-1.15$ & 0.17 \\
\hline PR: Prevalence rate. Cl95\% Confidence Interval 95. & & & \\
\hline a Univariate regression using generalized linear model & & \\
\hline value of 0.86 mm is considered as anormal carotide medial intima thickness. & \\
\hline & & & \\
\hline
\end{tabular}

In the crude analysis, each point increase in the non-glucose MSSS Z score, the risk of altered CIMT increases by 55\% PR 1.55 (CI95\% 1.05 to 2.28). Adjusting for age, sex, and HbA1c, MSSS also showed association PR 1.59 (Cl 95\% 1.09 to 2.35; $p=0.017$ ). (Table 4) 
Table 4

Multivariate analysis of the severity score of metabolic syndrome without glycemia for the thickness of the medial carotid intima-media in subjects with diabetes mellitus without cardiovascular disease at Hospital Edgardo Rebagliati.

\begin{tabular}{|c|c|c|c|c|c|c|c|c|c|}
\hline & \multicolumn{3}{|c|}{ Bivariate } & \multicolumn{3}{|c|}{$\begin{array}{l}\text { Multivariate } \\
\text { model } 1^{a}\end{array}$} & \multicolumn{3}{|c|}{$\begin{array}{l}\text { Multivariate } \\
\text { model } 2^{\mathrm{b}}\end{array}$} \\
\hline & PR & Ci $95 \%$ & $P$ & PR & Ci $95 \%$ & $\mathrm{p}$ & PR & $\begin{array}{l}\mathrm{Ci} \\
95 \%\end{array}$ & $P$ \\
\hline $\begin{array}{l}\text { Non-glucose MSSS } \\
\text { (Z score) }\end{array}$ & 1.55 & $\begin{array}{l}1.05- \\
2.28\end{array}$ & 0.01 & 1.54 & $\begin{array}{l}1.07- \\
2.22\end{array}$ & 0.02 & 1.59 & $\begin{array}{l}1.09- \\
2.35\end{array}$ & 0.017 \\
\hline Age (years old) & 1.06 & $\begin{array}{l}1.03- \\
1.09\end{array}$ & 0.000 & 1.06 & $\begin{array}{l}1.04- \\
1.09\end{array}$ & 0.000 & 1.06 & $\begin{array}{l}1.04- \\
1.09\end{array}$ & 0.000 \\
\hline Male & 1.69 & $\begin{array}{l}1.09- \\
2.63\end{array}$ & 0.018 & 0.95 & $\begin{array}{l}0.57- \\
1.57\end{array}$ & 0.84 & 0.91 & $\begin{array}{l}0.55- \\
1.50\end{array}$ & 0.71 \\
\hline A1c (\%) & 0.95 & $\begin{array}{l}0.86- \\
1.06\end{array}$ & 0.41 & & & & 0.96 & $\begin{array}{l}0.86- \\
1.07\end{array}$ & 0.53 \\
\hline
\end{tabular}

PR: Prevalence rate. CI95\% Confidence Interval 95\%. MSSS: Metabolic síndrome severity score.

a Multivariate regression using a generalized linear model with robust variance and Poisson distribution. A value of $0.86 \mathrm{~mm}$ is considered as abnormal carotid medial intima thickness.

${ }^{a}$ Model 1: Adjusted to age and sex. ${ }^{b}$ Model 2: Adjusted to age, sex, and A1c.

\section{Discussion}

MSSS is a prediction model developed from the National Health and Nutrition Examination Survey (NHANES) database. It must be convenient to validate outcome studies in different populations such as Latin American subjects to answer whether this prediction model can predict subclinical atherosclerosis as an early marker of CV events. In the present study, only the non-glucose MSSS definition showed the best diagnostic discrimination for elevated CIMT and presented a weak performance. The original MSSS did not show any discrimination in this population.

MSSS performed a significant association with future CVD among type 2 DM subjects from the Atherosclerosis Risk in Communities study (ARIC) (9). This cohort study found that MSSS and nonglucose MSSS at baseline were associated with incident CVD HR 1.29 ( $95 \% \mathrm{Cl} 1.21-1.39 ; \mathrm{p}<0.001$ ). and HR $1.42(95 \% \mathrm{Cl} 1.24-1.62 ; \mathrm{p}<0.001)$, respectively. This outcome study explains our better predictive ability of non-glucose MSSS to detect elevated CIMT than the original MSSS.

We did not find studies related to the association between MSSS and subclinical atherosclerosis as a surrogate marker of cardiovascular risk. Gurka et al. showed that MSSS has an excellent predictive performance of cardiovascular risk if glucose is not considered (9) or even when fasting values is replaced for non-fasting values into this model (11). The independent association of non-glucose- 
modified MSSS with cardiovascular risk might be explained for a possible weakness of glycemic status for detecting CIMT. Other risk factors as age, male sex, high-density-lipoprotein cholesterol, and total cholesterol also influence their development (12). However, glycemic parameters as post-prandial glucose (13) and glycemic variability are associated as independent risk factors for CIMT (14). The oxidative stress related to glucose fluctuations could explain this association. So glycemic control is an essential therapeutic intervention to decrease the subclinical atherosclerosis process (15).

DM and MS are associated with atherosclerotic findings as coronary calcium content, abdominal aortic calcification, elevated CIMT, and abnormal ankle-brachial index (ABI). These parameters, alone or combined, with greater cardiovascular risk rate (16). CIMT is one of the earliest surrogates of subclinical cardiovascular disease, and its measurement is easy to use even in-office settings, although its interpretation is operator dependent. Additionally, identifying biomarkers with the ability to predict early structural change, such as CIMT, should be an essential tool for modifying the atherosclerosis process's natural history as a primary prevention strategy for CVD (17-21).

As a weakness, the study stopped due to the SARS CoV 2 pandemic, and the original sample size did not complete, although the trend would not change in light of the results. Another limitation was that cardiovascular disease background was referred for the subjects without any assessment to rule out subclinical coronary disease. We selected the subjects by non-random sampling from a reference hospital and a primary care center and did not extrapolate beyond the study population. Finally, the small number of males and a wide age range could miss estimating the true prevalence of altered CIMT. As a strength, we evaluated the carotid intima-media thickness with the appropriate technique by on a highresolution ultrasound and a trained operator.

\section{Conclusions}

Our results show that non-glucose modified MSSS had the greatest accuracy for detecting CIMT compared with MS-ATP III, MS-harmonizing criteria, and original MSSS. Further studies are necessary to evaluate ultrasonography's clinical utility as an early intervention to reduce the risk of CIMT progression. Also, to evaluate the role of metabolic syndrome in the development of subclinical atherosclerosis.

\section{Declarations}

\section{Ethics approval and consent to participate:}

This study have been performed in accordance with the Declaration of Helsinki and it had been approved by an institutional ethics committee of Edgardo Rebagliati Martins Hospital.

President's committee: Dr. Julio César Alfaro Mantilla Committee address: Hospital Nacional Edgardo Rebagliati Martins. Avenida Edgardo Rebagliati 490, Jesús María, Lima., Perú. 
Phone number: 511-2654901, annex: 3080

email: comitedeeticadhed@essalud.gob.pe.

Informed consent to participate in the study wasobtained from participants. The informed consent document was approved by the institutional ethics committee.

\section{Consent for publication:}

Not applicable for that section.

\section{Availability of data and materials:}

The datasets used and/or analysed during the current study are available from the corresponding author on reasonable request.

\section{Competing interests:}

The authors declare to have no compelling interests with this article.

\section{Funding:}

This study was funded by the Institute for Health Technology Assessment and Research - IETSI, EsSalud Peru, through the 2018 Kaelin Award (Resolution No. 71 and 77-IETSI-ESSALUD-2018).

\section{Authors' contributions:}

All authors designed the study and collected the data. ATG, DU, and LMT recollected information. MYA performed statistical analyses. ATG and MYA participated in the interpretation of the results. MYA and ATG performed in the writing of the manuscript. All authors approved the final version of the manuscript.

\section{Acknowledgements:}

Not applicable for that section.

\section{References}

1. Gepner AD, Young R, Delaney JA, Tattersall MC, Blaha MJ, Post WS, et al. Comparison of Coronary Artery Calcium Presence, Carotid Plaque Presence, and Carotid Intima-Media Thickness for Cardiovascular Disease Prediction in the Multi-Ethnic Study of Atherosclerosis. Circ Cardiovasc Imaging [Internet]. 2015 Jan;8(1). Available from:

https://www.ahajournals.org/doi/10.1161/CIRCIMAGING.114.002262

2. Expert Panel on Detection, Evaluation, and Treatment of High Blood Cholesterol in Adults. Executive Summary of the Third Report of the National Cholesterol Education Program (NCEP) Expert Panel on 
Detection, Evaluation, and Treatment of High Blood Cholesterol in Adults (Adult Treatment Panel III). JAMA J Am Med Assoc. 2001 May 16;285(19):2486-97.

3. Alberti KGMM, Eckel RH, Grundy SM, Zimmet PZ, Cleeman JI, Donato KA, et al. Harmonizing the Metabolic Syndrome: A Joint Interim Statement of the International Diabetes Federation Task Force on Epidemiology and Prevention; National Heart, Lung, and Blood Institute; American Heart Association; World Heart Federation; International Atherosclerosis Society; and International Association for the Study of Obesity. Circulation. 2009 Oct 20;120(16):1640-5.

4. Grundy SM, Cleeman JI, Daniels SR, Donato KA, Eckel RH, Franklin BA, et al. Diagnosis and Management of the Metabolic Syndrome: An American Heart Association/National Heart, Lung, and Blood Institute Scientific Statement. Circulation. 2005 Oct 25;112(17):2735-52.

5. Chen K, Lindsey JB, Khera A, Lemos JAD, Ayers CR, Goyal A, et al. Independent associations between metabolic syndrome, diabetes mellitus and atherosclerosis: observations from the Dallas Heart Study. Diab Vasc Dis Res. 2008 Jun 1;5(2):96-101.

6. Ingelsson E, Sullivan LM, Murabito JM, Fox CS, Benjamin EJ, Polak JF, et al. Prevalence and prognostic impact of subclinical cardiovascular disease in individuals with the metabolic syndrome and diabetes. Clin Diabetol. 2007;8(8-9):315-29.

7. Gurka MJ, Ice CL, Sun SS, DeBoer MD. A confirmatory factor analysis of the metabolic syndrome in adolescents: an examination of sex and racial/ethnic differences. Cardiovasc Diabetol. 2012;11(1):128.

8. DeBoer MD, Gurka MJ, Morrison JA, Woo JG. Inter-relationships between the severity of metabolic syndrome, insulin and adiponectin and their relationship to future type 2 diabetes and cardiovascular disease. Int J Obes. 2016 Sep;40(9):1353-9.

9. Gurka MJ, Guo Y, Filipp SL, DeBoer MD. Metabolic syndrome severity is significantly associated with future coronary heart disease in Type 2 diabetes. Cardiovasc Diabetol. 2018 Dec;17(1):17.

10. DeBoer MD, Filipp SL, Musani SK, Sims M, Okusa MD, Gurka M. Metabolic Syndrome Severity and Risk of CKD and Worsened GFR: The Jackson Heart Study. Kidney Blood Press Res. 2018;43(2):55567.

11. DeBoer MD, Filipp SL, Gurka MJ. Associations of a metabolic syndrome severity score with coronary heart disease and diabetes in fasting vs. non-fasting individuals. Nutr Metab Cardiovasc Dis. 2020 Jan;30(1):92-8.

12. Temelkova-Kurktschiev T, Koehler C, Schaper F, Fuecker K, Siegert G, Henkel E, et al. Relationship between fasting plasma glucose, atherosclerosis risk factors and carotid intima media thickness in non-diabetic individuals. Diabetologia. 1998 May 27;41(6):706-12.

13. Esposito K, Ciotola M, Carleo D, Schisano B, Sardelli L, Di Tommaso D, et al. Post-Meal Glucose Peaks at Home Associate with Carotid Intima-Media Thickness in Type 2 Diabetes. J Clin Endocrinol Metab. 2008 Apr;93(4):1345-50.

14. Liu M, Ao L, Hu X, Ma J, Bao K, Gu Y, et al. Influence of blood glucose fluctuation, C-peptide level and conventional risk factors on carotid artery intima-media thickness in Chinese Han patients with type 
2 diabetes mellitus. Eur J Med Res. 2019 Dec;24(1):13.

15. Barbieri M, Rizzo MR, Marfella R, Boccardi V, Esposito A, Pansini A, et al. Decreased carotid atherosclerotic process by control of daily acute glucose fluctuations in diabetic patients treated by DPP-IV inhibitors. Atherosclerosis. 2013 Apr;227(2):349-54.

16. Zhao Y, Evans MA, Allison MA, Bertoni AG, Budoff MJ, Criqui MH, et al. Multisite atherosclerosis in subjects with metabolic syndrome and diabetes and relation to cardiovascular events: The MultiEthnic Study of Atherosclerosis. Atherosclerosis. 2019 Mar;282:202-9.

17. Matsumoto K, Sera Y, Abe Y, Tominaga T, Yeki Y, Miyake S. Metformin attenuates progression of carotid arterial wall thickness in patients with type 2 diabetes. Diabetes Res Clin Pract. 2004 Jun;64(3):225-8.

18. Katakami N, Yamasaki Y, Hayaishi-Okano R, Ohtoshi K, Kaneto H, Matsuhisa M, et al. Metformin or gliclazide, rather than glibenclamide, attenuate progression of carotid intima-media thickness in subjects with type 2 diabetes. Diabetologia. 2004 Nov;47(11):1906-13.

19. Rizzo M, Rizvi AA, Patti AM, Nikolic D, Giglio RV, Castellino G, et al. Liraglutide improves metabolic parameters and carotid intima-media thickness in diabetic patients with the metabolic syndrome: an 18-month prospective study. Cardiovasc Diabetol. 2016 Dec;15(1):162.

20. Langenfeld MR, Forst T, Hohberg C, Kann P, Lübben G, Konrad T, et al. Pioglitazone Decreases Carotid Intima-Media Thickness Independently of Glycemic Control in Patients With Type 2 Diabetes Mellitus: Results From a Controlled Randomized Study. Circulation. 2005 May 17;111(19):2525-31.

21. Chiavaroli L, Mirrahimi A, Ireland C, Mitchell S, Sahye-Pudaruth S, Coveney J, et al. Cross-sectional associations between dietary intake and carotid intima media thickness in type 2 diabetes: baseline data from a randomised trial. BMJ Open. 2017 Mar;7(3):e015026.

\section{Figures}




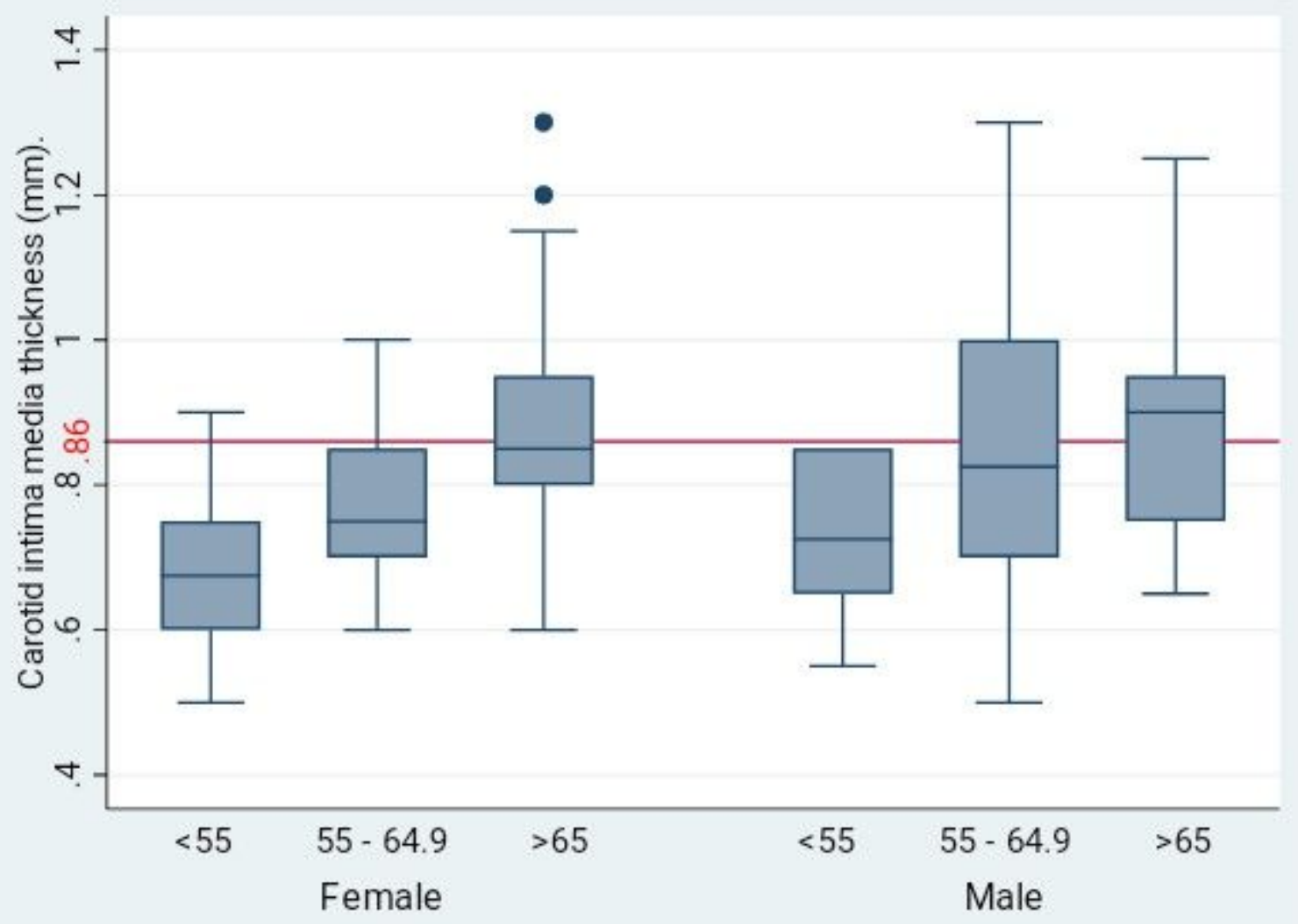

Figure 1

Carotid intima-media thickness according to sex and age group in subjects with diabetes mellitus without cardiovascular disease at the Edgardo Rebagliati Hospital. A value of $0.86 \mathrm{~mm}$ was considered as abnormal carotid medial intima thickness. 54 subjects $(29.4 \%$ ) presented abnormal CMIT, $24.5 \%$ in female and $41.5 \%$ in male. 


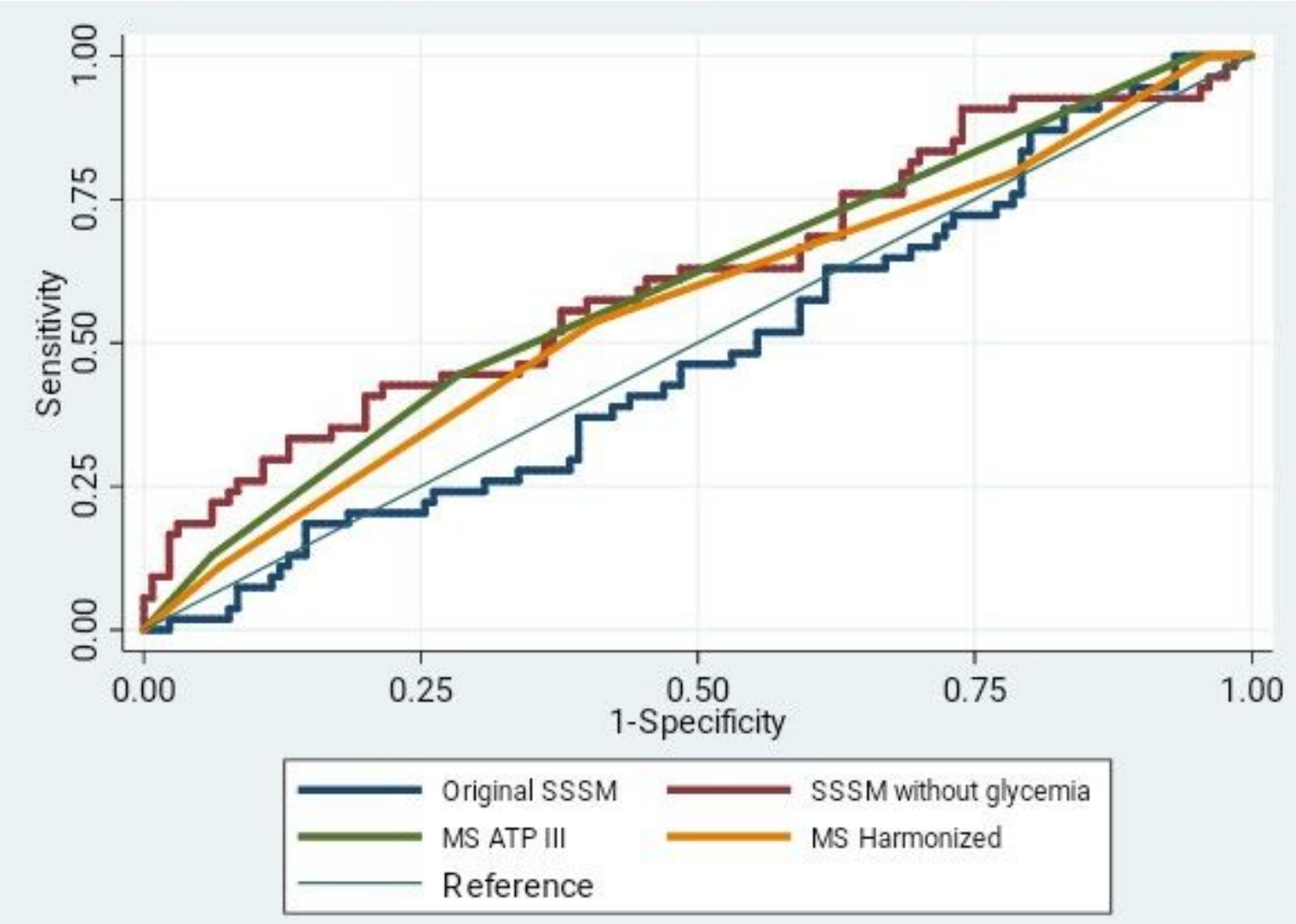

Figure 2

The area under the ROC curve of the metabolic syndrome severity score and classic definitions of metabolic syndrome in subjects with diabetes mellitus and no cardiovascular disease at the Edgardo Rebagliati Martins hospital. MSSS: Metabolic síndrome severity score. MS ATP III: 3 of 5 criteria according to Adult Treatment Panel III. MS Harmonizing criteria: : 3 of 5 criteria according to Harmonized Consensus. A value of $0.86 \mathrm{~mm}$ was considered as abnormal carotid medial intima thickness. 


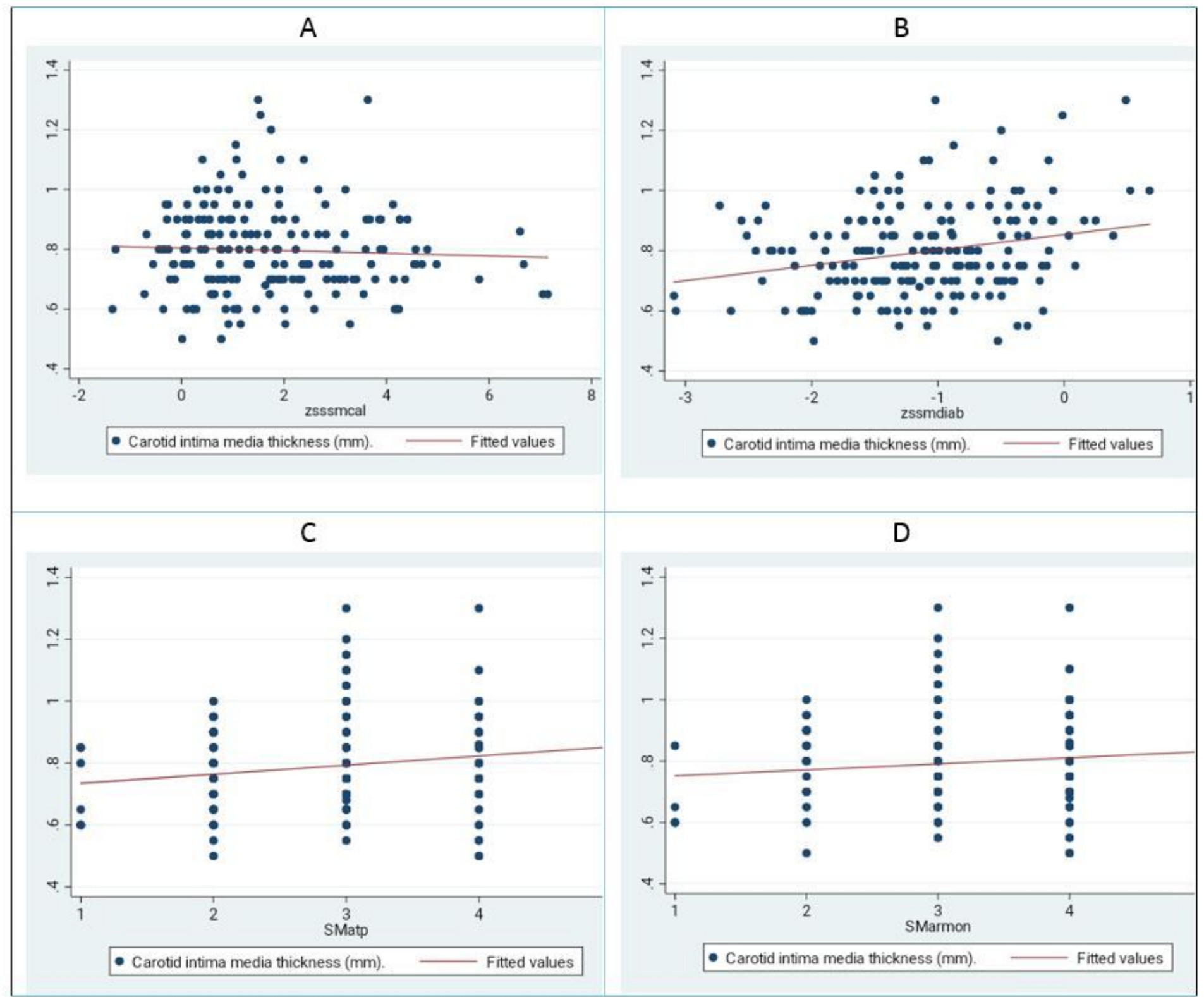

Figure 3

Correlation between carotid intima-media thickness with a severity score of metabolic syndrome and classic MS definitions in subjects with diabetes mellitus without cardiovascular disease at Rebagliati hospital. A. CIMT and original MSSS Spearman correlation $=-0.05 ; p=0.46$. B. CIMT and MSSS without glycemia Spearman correlation $=0.19 ; p=0.008$. . C. CIMT and ATP III SM criterio Spearman correlation $=0.18 ; p=0.01$. D. CIMT and Harmonizing MS criterio Spearmna correlation=0.11; $p=0.12$. 